acuity which appears in the text of the paperthat is, " $6 / 18$ or worse in the better eye, both eyes using best correction."

Our error was to attribute this definition to the WHO both in the text and in the heading of table I. We apologise for any confusion we may have caused to readers.

David H Stone

Greater Glasgow Health Board, Glasgow

Pfizer (Central Research),

Sandwich, Kent ${ }^{1}$ World Health Organisation, The Prevention of Blindness,
WHO Technical Report Series No 518. Geneva,
WHO, 1973.

\section{Treatment of rheumatoid arthritis}

SIR,-I read with intersst the letter from Dr R Luukkainen and others (25 November, p 1501).

I quite agree that gold or other diseasemodifying drugs need to be used in several situations in the treatment of rheumatoid arthritis. Indeed, in the article (14 October, p 1068) I listed four different indications. The first covers the situation described in their letter: "The most common group includes those patients with widespread active disease, usually in the first year of disease, whose disease activity cannot be controlled despite the trial of several non-steroidal antiinflammatory drugs in effective dosage." The second group was those with progressive radiological damage, the third group those with systemic features, and the fourth group those with long-standing disease but with continuing activity. This will show that we are in complete agreement.

I am not sure that it is correct to say that the result is worse if gold treatment is initiated later. One can be categorical and say that patients started on gold later in the course of the disease require a greater total dose (average $920 \mathrm{mg}$, range $325-2780 \mathrm{mg}$ ) given as $50-\mathrm{mg}$ injections at weekly intervals before improving in comparison with those started earlier (average $591 \mathrm{mg}$, range $160-1180 \mathrm{mg}$ ). The quality of the response may be comparable.

Northwick Park Hospital and Clinical Research Centre, Harrow, Middx

'Gumpel, J M, Rheumatology and Rehabilitation, 1976,
15, 217.

\section{Metoclopramide in young children}

SIR,-Despite the recent attention drawn to the adverse toxic effects of metoclopramide in children the drug continues in common usage by family practitioners in this region.

Drs J A Sills and E J Glass (5 August, p 431) mention the narrow margin between toxic and therapeutic dosage of metoclopramide and have reported two children who required admission to hospital following "convulsions." Recently we have seen a further two children whose initial symptoms of pyrexia and vomiting were treated with metoclopramide and antibiotics. Within six hours of metoclopramide administration both febrile children were admitted to hospital with severe extrapyramidal dystonia, including opisthotonos and marked neck retraction. As the possibility of meningitis could not be excluded both children had lumbar punctures that yielded a normal cerebrospinal fluid. While the definitive diagnosis of dystonic reaction could have been made initially, the outcome of missing a purulent meningitis is too serious to omit a spinal tap. Conversely, although metoclopramide produces a satisfying symptomatic relief of vomiting in many instances, as Dr A Bloch (14 October, p 1092) points out, the resultant effect has actually masked the diagnosis of meningitis in three infants.

The known indications for the use of this efficacious drug have been well documented ${ }^{1}$ and the danger of overdosage outlined. If the daily dose of metoclopramide exceeds $0.5 \mathrm{mg} /$ $\mathrm{kg}$ /day the incidence of dystonic reactions is markedly increased. There is the all too common temptation by parents to administer more than the prescribed dose in order to abate the symptoms more rapidly. Simpler and safer measures are recognised that are equally efficacious in preventing vomiting in children. The use of metoclopramide for infants and young children should be discouraged and more attention paid to the primary diagnosis rather than to the symptoms it produces.

G J REYNOLDS

University Department of Child Health,

Alder Hey Children's Hospital,

A.iverpool

${ }^{1}$ Nimmo, W S, Prescribers fournal, 1977, 17, 90.

\section{Management of defects of vision in} early childhood

SIR,-In your series "ABC of Ophthalmology" Mr P A Gardiner states (18 November, p 1411) that "judging distances . . . requires much experience and experiment." While I would not dispute that the ability to make absolute judgments of distance develops during childhood, there is evidence to suggest that even very young infants may be able to judge relative distance. Some years ago Bower demonstrated experimentally ${ }^{1}$ that infants less than 2 months of age were able to discriminate successfully between different distances when the only cue available to them was that of motion parallax, the term used to refer to the fact that the images of objects at different distances move across the retina at different speeds during lateral movement of the head.

We can detect whether an object is in front of or behind the plane of fixation by relying on stereoscopic vision. The mechanism underlying stereopsis can be illustrated by means of what are known as random dot stereograms. A pair of stereograms is constructed such that dots generated randomly by computer appear more or less identically in each member of the pair. The only difference between the two stereograms is that in one a central region of dots is shifted slightly in a horizontal direction relative to its position in the other. Viewed monocularly each stereogram appears as a random array of dots. If, however, each member of the pair is viewed by a different eye by means of a stereoscope of cross-polarised filters the central region of displaced dots appears to stand out dramatically in depth. ${ }^{2}$ This demonstrates that stereopsis depends upon the horizontal disparity between the two images of the same object at the left and right eyes. Recently two out of four 2-month-old infants gave evidence of being able to discriminate between sets of random dot stereo-pairs having different horizontal disparities. ${ }^{3}$ As these infants showed no differential response to sets of stereograms differin in vertical disparity it is difficult to resist the conclusion that some degree of stereoscopic vision may be present even at this early age. In support of this argument it may be noted that, like normal adults and children but unlike stereo-defective subjects, babies aged as little as 2 months show enhanced visual evoked potentials with binocular as compared to monocular viewing. ${ }^{4}$ At the very least this implies that information from the two eyes is integrated at some level in the immature brain.

Neurophysiological research with cats and monkeys has shown that the vast majority of neurones in the striate cortex can be stimulated by input presented to either the left or the right eye. In the adult cat or monkey such binocular cortical neurones fire maximally when separate stimuli fall simultaneously on the two retinas. However, the exact position of the stimuli is crucial and differs slightly for one eye relative to the other, the preferred disparity differing for different cortical cells. These binocular cells are therefore thought to act as disparity detectors and are thus clearly implicated in the phenomenon of stereopsis. ${ }^{5}$

The link between such work and humans is this. Binocular cortical neurones are present as soon as the animal opens its eyes. Suturing of one eye from birth or a surgically induced squint, however, results in a drastic reduction in the proportion of binocularly driven neurones encountered during later microelectrode exploration. ${ }^{6}$ As is well known, human strabismic patients rarely possess stereoscopic vision even if the defect was surgically corrected at an early age. Behavioural testing of patients having strabismic or anisometropic amblyopia reveals that, unlike most normal subjects, they show little if any transfer of certain monocularly generated perceptual effects from the viewing to the non-viewing eye. This is consistent with the notion that such patients are deficient in cortical binocular neurones as a result of their early anomalous visual experience.?

It appears that the developing brain can be modified by visual experience other than through amblyopic abnormality. Shlaer raised kittens with a prism permanently in front of one eye such that the scene viewed by that eye was shifted relative to the other eye. ${ }^{8}$ Subsequent recording with microelectrodes suggested that binocular cortical neurones had adjusted to the disparity induced by the prism. More recent experiments have confirmed this early plasticity of the visual system. Given, then, that cortical binocularity drops out in cases of squint yet is modified so as to accommodate relatively less severe prism-induced distortions, it seems likely, in view of the evidence discussed above, that the human infant is born with a functional binocular visual system that is able to operate only within certain predetermined limits. Gradually the system becomes more finely tuned in accordance with the infant's experience. This would, of course, be adaptive in allowing the brain to compensate for changes in ocular alignment and inter-eye distance as the infant grows older.

\section{Psychology Department}

University College,

Swansea

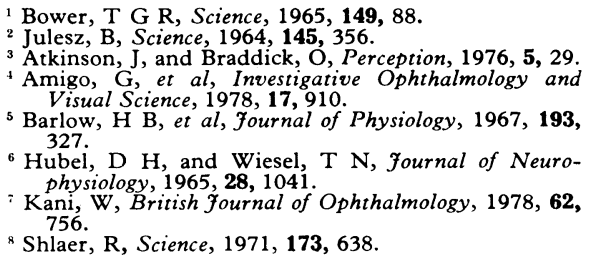

Alan A Beaton

\section{Postanaesthetic oxygen}

SIR,-Your recent leading article on this subject (25 November, p 1452) suggests that oxygen "should be prescribed in a known concentration for a specific time for those who need it." The elderly, patients with additional 
cardiovascular disease, and patients who have had upper abdominal or thoracic surgery or prolonged nitrous oxide anaesthesia are among those who, you suggest, should be given routine oxygen postoperatively. Should this large group of patients have arterial $\mathrm{PO}_{2}$ and $\mathrm{PCO}_{2}$ measurements before, during, and after oxygen therapy? This would necessitate repeated stabs or an indwelling arterial line. Although Nunn ${ }^{1}$ felt there was no alternative to arterial puncture and direct measurement of $\mathrm{PO}_{2}$ we $^{2}$ have shown, using paired radial artery samples and arterialised capillary blood from the ear lobe, a highly significant correlation between both methods for $\mathrm{Po}_{2}$ determination. Respiratory care in the surgical unit would be improved by more frequent blood gas analysis, and arterialised capillary blood, when carefully collected, gives as accurate results as arteria blood.

For how long should oxygen be prescribed after general anaesthesia? Many surgical units routinely treat selected patients with oxygen for the first $24 \mathrm{~h}$ postoperatively. However, we $^{3}$ have shown that the mean percentage decrease in $\mathrm{PO}_{2}$ following upper abdominal surgery was greatest during the second and third postoperative days, remained greater than $20^{\circ}$, for the first four days, and tended to return to preoperative values towards the end of the first week. This suggests that when oxygen is indicated during the first postoperative day it is illogical to stop it after $24 \mathrm{~h}$ unless cessation is accompanied by seria observation of $\mathrm{PO}_{2}$ levels. Further treatment with oxygen should take into consideration the necessity for early mobilisation, oxygeninduced pulmonary toxicity, and the need to keep the arterial $\mathrm{Po}_{2}$ above $8 \mathrm{kPa}(60 \mathrm{~mm} \mathrm{Hg})$.

P S PARFREY

Medical Unit, London Hospital

London E1

Paul J Harte

J P QUINLAN

$M$ P BRADY

Department of Surgery,

University College,

Nunn, J F, Applied Respiratory Physiology. London, Butterworths, 1969

Parfrey, P S, et al, British fournal of Surgery, 1977, 64,

Parfrey, P S, et al, British fournal of Surgery, 1977, 64,
390.

\section{Naming of drugs}

SIR,-I heartily agree with Dr G A MacGregor's (18 November, p 1433) view that the multiplicity of names for one and the same drug is fraught with dangers. I do not, however, believe with you that the advice to use approved rather than proprietary names when prescribing drugs provides a satisfactory solution. This is a losing battle. After all, it is the proprietary name that appears in large letters on the bottle of tablets we get from the drug house, that appears in our medical journals and on the advertisements that come daily through our letterboxes, whereas the approved name is in tiny print and often difficult to find. Furthermore, in $M I M S$ drugs are listed according to their proprietary and not according to their approved names. Approved names, especially when attempts are made to indicate the pharmacological group to which they belong, become clumsy tonguetwisters like chlordiazepoxide or tranylcypro- mine, which makes them difficult to remember and to use when communicating with the nursing staff, not to mention the patients. A further hazard in these days of world travel lies in the fact that even some of our approved names are quite unknown abroad, including the USA, so that a patient travelling to foreign country might be in real trouble if he has left his tablets behind and tries to get them replaced abroad.

To my mind the best, if utopian, solution would be an international agreement: one single name for each drug. It should be simple, easily remembered, and universally understood. Should the prescriber be anxious to have a particular brand he should put the manufacturer's name in brackets behind the drug's name. It has worked so well for so long with insulin; why not for other drugs too?

\section{University Department of Therapeutics}

\section{R SCHNEIDER}

and Clinical Pharmacology,

Queen Elizabeth Hospital,

Birmingham

\section{Successful defibrillation in general practice}

SIR,-Drs A D Shaw and J L Baird (30 September, $p$ 958) suggested that their experience of resuscitation after cardiac arrest in general practice was unique. We are glad to say that it is not unique as we are able to report a further case.

The patient, a woman, suffered cardiac arrest in our surgery. External cardiac massage was started, an intratracheal tube was passed, and an intravenous line inserted. One of the partners went to the GP hospital and collected the electrocardiograph, which took well over five minutes; once attached it showed ventricular fibrillation. She was given $1 \mathrm{~g}$ of procainamide with no effect. At about this point the ambulance arrived, but unfortunately it did not have a defibrillator on board and was therefore sent to the district hospital to collect the recently donated portable machine, which naturally took a considerable amount of time, say 10 minutes. Luckily the casualty sister arrived with the defibrillator and a box of emergency drugs so that we were able to give the patient some bicarbonate. After problems with ventricular tachycardia asystole, a total of four defibrillations, and a mixture of drugs she was dispatched to the coronary care unit in sinus rhythm. She has now returned home to live alone with minimal amount of residual cardiac failure.

D J DICKSON

J M CRUICKSHANK

D W L SMITH

Northallerton, $\mathrm{N}$ Yorks

lack of communication and, more important, the service either group is able to give the patient is therefore impaired. I strongly fee that medicine has now become such a vast subject that there is a greater need than ever for each group, expert in its own particular branch of the science, to work with the other groups to provide an effective health service. Although the prophets of doom foretell the imminent destruction of the NHS, I look forward to an improved service in which I will be able to utilise my pharmaceutical education to its full potential to the benefit of the rest of the medical profession and the patients.

Bridgwater, Sornerset

Steven A Pleece

\section{Terminology of enuresis}

SIR,-The introduction of the term "recentonset enuresis" by Mr Paul H Abrams and others (4 November, $p$ 1258) to describe nocturnal incontinence due to chronic retention requires comment. At the recent meeting of the International Continence Society in Manchester an attempt was made to clarify the meaning of the term "enuresis" with little success. Enuresis simply means incontinence of urine, but by common usage has come to mean bed-wetting in children. It is a symptom and not a disease entity. During the time a child is "learning" bladder control incontinence is normal, only becoming abnorma when delay in gaining control is prolonged beyond 5 years of age. Keith Turner $^{1}$ has defined nocturnal enuresis as persistent involuntary micturition during sleep in the absence of demonstrable pathology. It is probably true that children who gain control both by day and by night and then become incontinent in the absence of demonstrable organic disease have a psychological basis for the incontinence. ${ }^{2}$ This group has been termed secondary or "onset" enuresis. Neither of these terms gives a clear description of the suggested aetiology. To clarify the situation it would seem that the term enuresis should be used in children or adults who fail to gain bladder control and as evidence of this have persistently wet the bed all their lives and have no demonstrable organic disease. I feel the introduction of the term "recent-onset enuresis" to describe nocturnal incontinence of known cause is a retrograde step and will add further to the confusion.

JOHN R HINDMARSH

Department of Surgery (Urology),

Western General Hospital Edinburgh

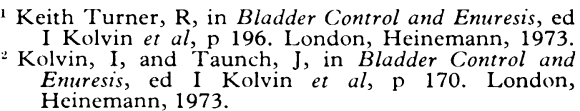

\section{Collaboration between GPs and}

pharmacists

SIR,-As a pharmacist working in retail pharmacy I am very concerned by the lack of co-ordination between general practitioners and retail pharmacists. Although I have no problems with my particular local practice, I find that if I have to refer back to other prescribers for various reasons I am not accepted as being able to discuss drug therapy on a level with them.

I do not wish to use your journal merely to voice my moans, but $I$ do feel that both GPs and pharmacists are the poorer for this

\section{Deficiencies in parenteral nutrition}

SIR,-Your leading article (30 September, p 913) wisely stresses that the advantages and disadvantages of parenteral feeding need to be carefully balanced, and jaundice and cholestasis are mentioned among the hazards associated with this form of therapy. The author of the reference cited concluded that cholestasis and jaundice occurring in :he patients whom he studied were produced by the intravenous amino-acid solution Travasol 1 In Great 